\title{
Case Report \\ Sepsis and Pleural Empyema Caused by Streptococcus pyogenes after Influenza A Virus Infection
}

\author{
Fumihiro Ochi (D), Hisamichi Tauchi, Toshihiro Jogamoto, Hiromitsu Miura, \\ Tomozo Moritani, Kozo Nagai, and Eiichi Ishii \\ Department of Pediatrics, Ehime University Graduate School of Medicine, Ehime, Toon, Japan \\ Correspondence should be addressed to Fumihiro Ochi; fmochi2000@yahoo.co.jp
}

Received 7 May 2018; Accepted 29 August 2018; Published 23 September 2018

Academic Editor: Nina L. Shapiro

Copyright ( $\odot 2018$ Fumihiro Ochi et al. This is an open access article distributed under the Creative Commons Attribution License, which permits unrestricted use, distribution, and reproduction in any medium, provided the original work is properly cited.

\begin{abstract}
Streptococcus pyogenes (also referred to as group A streptococci, GAS) causes severe invasive diseases such as bacteremia, necrotizing fasciitis, pneumonia, osteomyelitis, septic arthritis, and toxic shock syndrome in children. However, there are only a few reports on pleural empyema caused by GAS in children. Here, we report the case of a 4-year-old boy who presented with pleural empyema due to GAS after influenza A virus infection. With intravenous antibiotic administration and continuous chesttube drainage, followed by video-assisted thoracoscopic surgery, his condition improved. During the clinical course, cytokines induced in response to the influenza virus, especially IL-1 $\beta$ and IL-10, were elevated 1 week after influenza A infection, but these decreased as the symptoms improved. Reportedly, the IL-10 production increases during influenza virus-bacteria superinfection. These observations suggest that the immunological mechanisms induced by the influenza virus can play an important role in influencing the susceptibility to secondary bacterial infections, such as GAS, in children.
\end{abstract}

\section{Introduction}

Lancefield group A beta-hemolytic streptococcus (GAS, Streptococcus pyogenes) causes a variety of infectious diseases in children; these range from common acute infections such as pharyngitis and impetigo to severe invasive diseases such as bacteremia, necrotizing fasciitis, pneumonia, osteomyelitis, septic arthritis, and toxic shock syndrome $[1,2]$. However, only few reports describing pleural empyema due to GAS in children are available. For example, Krenke et al. [3] reported that bacteria detected by culturing the pleural fluid in children with parapneumonic effusion/pleural empyema were mainly Streptococcus pneumoniae (66.7\%) or coagulase negative staphylococci $(14.7 \%)$ and only a small proportion of GAS (5.8\%).

Here, we report the case of a 4-year-old boy with pleural empyema due to GAS after infection with influenza A virus. In addition, we discuss the pathogenesis of severe GAS infection following influenza with regard to cytokine levels during the clinical course of GAS infection.

\section{Case Presentation}

A 4-year-old boy was treated for fever, mild cough, and nasal discharge at another hospital. Thereafter, he was diagnosed with influenza A infection and was treated with oseltamivir ( $4 \mathrm{mg} / \mathrm{kg} /$ day, 5 days). However, his condition deteriorated and fatigue, low activity, and breathing difficulty progressed; he was admitted to our hospital 7 days after the diagnosis of influenza A infection. He had no medical history of recurrent bacterial infections or growth failure. Physical examination at admission revealed remarkable respiratory distress and consciousness disturbance (Glasgow Coma Scale, E4V3M4). His body temperature was $38.0^{\circ} \mathrm{C}$, blood pressure was $126 / 77 \mathrm{mmHg}$, heart rate was 155 beats/min, respiratory rate was 60 breaths/min, and oxygen saturation was $90 \%$ at room air. Right breath sounds were reduced, and an end-inspiratory crackle was detected in the right upper lung. In addition, red, cracked lips, strawberry tongue, and trunk and bilateral feet erythema were observed. Neither bilateral conjunctival injection, cervical lymphadenopathy nor edema was detected. Laboratory examination revealed 


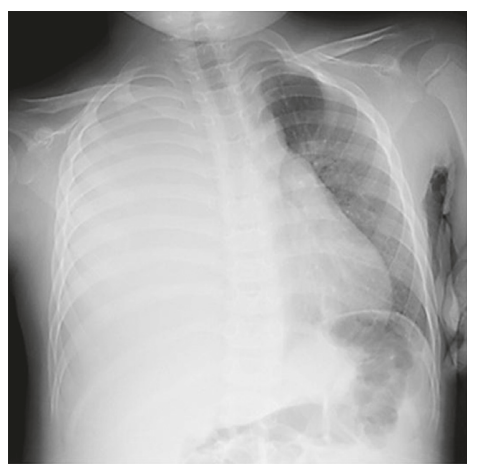

(a)

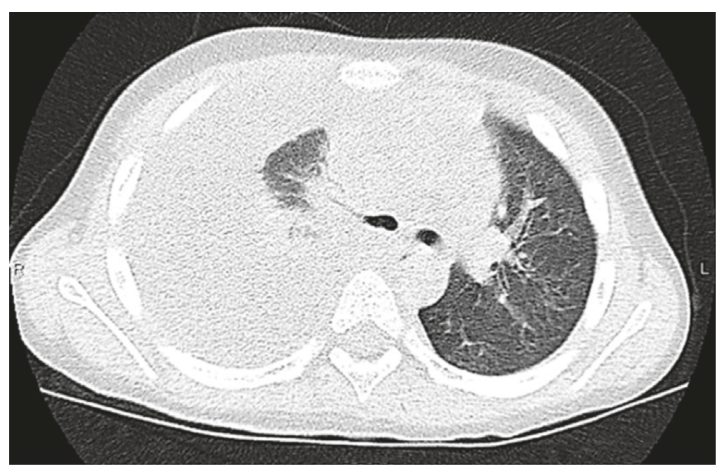

(b)

Figure 1: (a) Chest X-ray and (b) chest computed tomography scan of the thoracic region. The images indicate a large pleural empyema of a right pulmonary lesion.

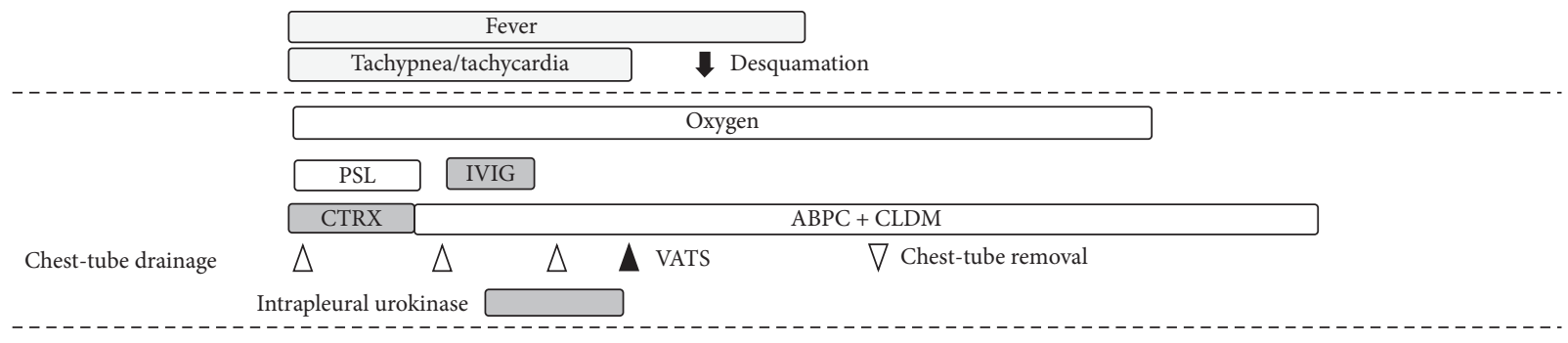

Pleural effusion culture $\quad+$ GAS $\quad$ - -
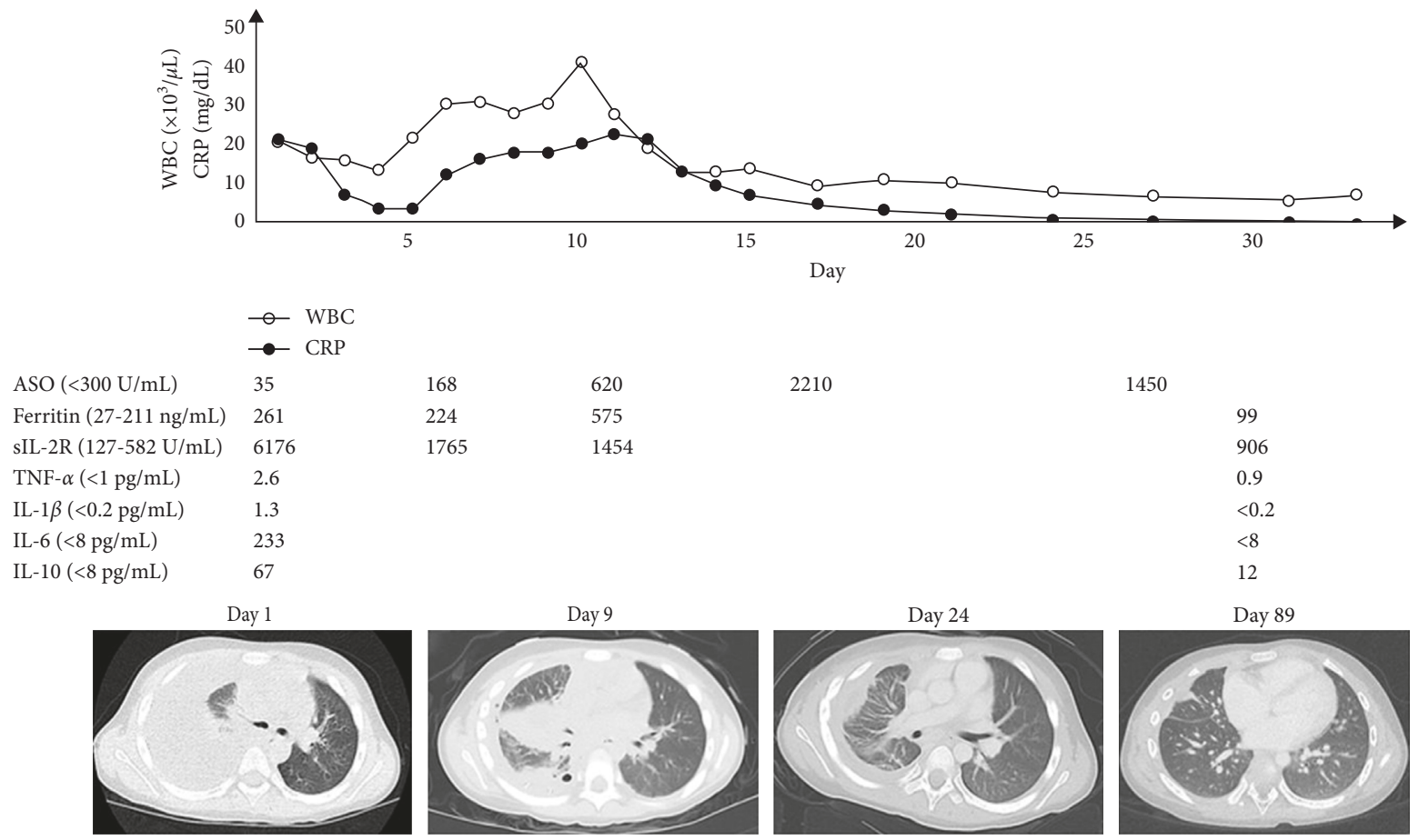

FIgURE 2: Clinical course of the patient. IL-1 $\beta$, IL-6, IL-10, and TNF- $\alpha$ were elevated 1 week after the influenza infection but normalized as the symptoms improved. GAS, Streptococcus pyogenes; PSL, prednisolone; sIL-2R, soluble interleukin-2 receptor; ASO, antistreptolysin O antibody; WBC, white blood cell counts; CRP; C-reactive protein, CTRX, ceftriaxone; ABPC, ampicillin; CLDM, clindamycin; IVIG, immunoglobulin; and VATS, video-assisted thoracoscopic surgery.

a white blood cell count (WBC) of $20,000 / \mu \mathrm{L}$ with $95.1 \%$ neutrophils, hemoglobin level of $14.0 \mathrm{~g} / \mathrm{dL}$, and platelet count of $22.7 \times 10^{4} / \mu \mathrm{L}$. Inflammatory biomarkers were elevated; C-reactive protein level was $20.54 \mathrm{mg} / \mathrm{dl}$, procalcitonin level was $45.23 \mathrm{ng} / \mathrm{mL}$, lactate dehydrogenase (LDH) level was $512 \mathrm{U} / \mathrm{L}$, ferritin level was $261 \mathrm{ng} / \mathrm{mL}$, and 


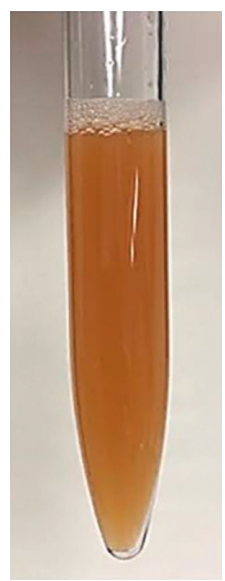

(a)

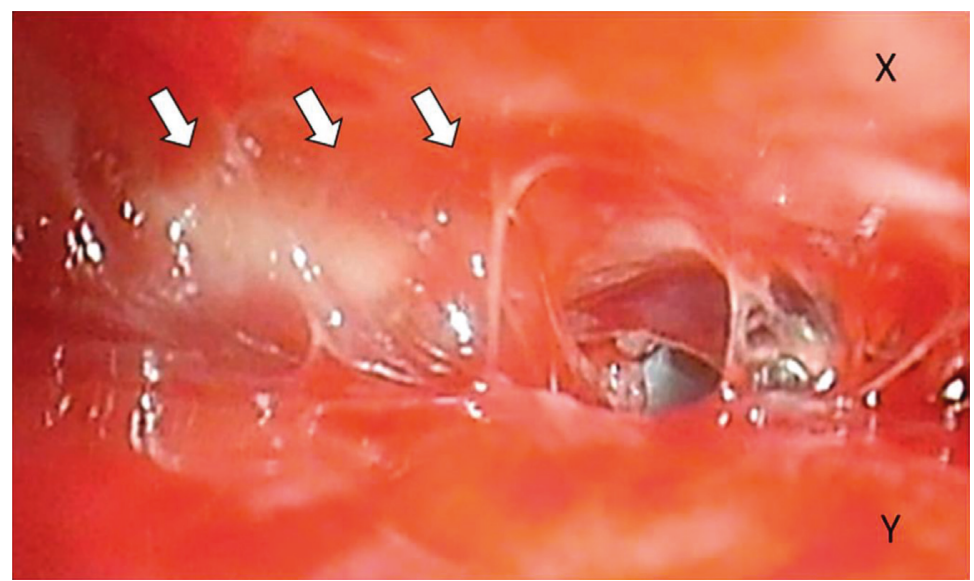

(b)

Figure 3: (a) Aspirated pus from the pleural empyema. (b) Operative thoracoscopic views obtained from video-assisted thoracoscopic surgery. White arrows indicate severe adhesion by fibrin between the parietal pleura $(\mathrm{X})$ and the pulmonary pleura (Y).

soluble interleukin-2 receptor (sIL-2R) level was $6,176 \mathrm{U} / \mathrm{mL}$. The levels of several cytokines were also increased: IL- $1 \beta$ was $1.3 \mathrm{pg} / \mathrm{mL}$; IL-6 was $233 \mathrm{pg} / \mathrm{mL}$; IL- 10 was $67 \mathrm{mg} / \mathrm{mL}$; and TNF- $\alpha$ was $2.6 \mathrm{pg} / \mathrm{mL}$, whereas IL-2, IL-3, IL-4, IL-5, and IL-12 were all normal. A chest X-ray and chest computed tomography revealed consolidation and a large-right pleural effusion (Figures 1(a) and 1(b)). Based on these findings, the patient was diagnosed with sepsis and pleural empyema due to GAS infection.

The clinical course of the patient is shown in Figure 2. Initially, continuous chest-tube drainage, intravenous administration of antibiotics (CTRX) and immunoglobulin $(150 \mathrm{mg} / \mathrm{kg} /$ day, 3 days), and prednisolone $(1 \mathrm{mg} / \mathrm{kg} /$ day, 3 days) were prescribed for sepsis and pleural empyema. The aspirated pleural fluid was serological with a yellowish brown color and $\mathrm{pH}$ of $7.002, \mathrm{WBC}$ of $33,900 / \mu \mathrm{L}$, protein of $4.7 \mathrm{~g} / \mathrm{dL}, \mathrm{LDH}$ of $9,121 \mathrm{U} / \mathrm{L}$, and adenosine deaminase of 173.7 U/L (Figure 3(a)). No bacteria were detected by blood culture, whereas GAS tests conducted on both pleural fluids and throat swab on day 1 after culture were positive. The genotype of GAS was found to be emm1/speA/speB/speF, which is known as a virulence factor gene. Based on this data, the antibiotics were changed from CTRX to ampicillin (ABPC) and clindamycin (CLDM). However, fever and tachypnea persisted. Alternatively, the chest tube was considered as being obstructed or failing to drain, and hence, the chest tube was replaced, and an additional fibrinolytic therapy (urokinase 40,000 units in $40 \mathrm{~mL} 0.9$ percent saline, intrapleural) was included; however, the patient's clinical condition still did not improve. On day 9, video-assisted thoracoscopic surgery (VATS) was performed to remove the thick fibrous septations. Thoracoscopy of the thoracic cavity revealed an adhered pulmonary and parietal pleura with fibrin; the cavity was then peeled off and washed using saline (Figure 3(b)). The patient's clinical condition improved following VATS, and he was discharged on day 33. All inflammatory biomarkers and cytokines had reduced to normal levels. At the time of the final follow-up, the patient had been healthy without any symptoms.

\section{Discussion}

GAS is a well-known causative pathogen of the upper respiratory tract and cutaneous infections and occasionally leads to parapneumonic effusion/pleural empyema. Sakai et al. described an invasive GAS infection with communityacquired pneumonia followed by pleural empyema that resulted in streptococcal toxic shock syndrome in a healthy male adult [2].

GAS strains express many bacterial virulence factors including protein $M$, streptolysins, and streptokinase. Of these, protein $\mathrm{M}$ is a major bacterial virulence factor that is encoded by the $\mathrm{emm}$ gene and shows resistance to phagocytosis. The emm 1 gene was most prevalent $(n=27,32.9 \%)$ and significantly related to poor outcomes among 82 invasive GAS isolates in Japan [4]. Furthermore, these invasive strains showed a highly significant association with the presence of the speA gene, which encodes the streptococcal superantigen [5]. Compatible with these findings, our isolate had emm1/speA genes, which is suggestive of a highly pathogenic strain.

Over recent years, the frequency of parapneumonic effusion/pleural empyema has increased in children with influenza A infection [6]. Furthermore, recent studies have attempted to elucidate the immunological mechanism of influenza virus complicated by bacterial superinfection. The secondary bacterial superinfection vulnerability typically surfaces 1 week after influenza infection [7]. In our case, the patient also incurred sepsis and pleural empyema as a result of GAS infection that surfaced 7 days after the onset of influenza A infection. These findings indicated the importance of immune status, particularly one week after influenza.

Robinson et al. [8] reported that influenza A virus inhibits bacteria-induced IL-1 $\beta$ production and impairs host defense against bacterial infection. Moreover, IL-10 deactivates macrophages and decreases the production of cytokines by $\mathrm{T}$ cells [9]; regulatory $\mathrm{T}\left(\mathrm{T}_{\mathrm{Reg}}\right)$ cells are also known to produce IL-10 during influenza virus infection 
[10]. As the production of the anti-inflammatory cytokine IL-10 has been shown to increase during influenza virusbacterial superinfection, it is possible that $\mathrm{T}_{\mathrm{Reg}}$ cells induce susceptibility to secondary bacterial infection [11]. Barthelemy et al. [12] reported that influenza A virus-induced release of IL-10 inhibited the antimicrobial activities of invariant natural killer T cells during invasive pneumococcal superinfection. In addition, neutralization of IL-10 with a specific antibody reduced mortality and S. pneumoniae growth in mice [13]. Interestingly, recent evidence has suggested that the serum IL-10 level is high in cases of rheumatic fever (RF) or rheumatic heart disease (RHD) caused by GAS, and IL-10 plays a vital role in the pathogenesis and contributes to the severity of RF/RHD [14]. These findings emphasized the importance of IL-10 in influenza virus-bacterial superinfection.

Our patient exhibited elevated levels of serum IL- $1 \beta$ and IL-10 after one week of influenza A infection, but they decreased as the symptoms improved. It is notable that the increased level of IL-10 was remarkable compared with that of IL- $1 \beta$, suggesting that cytokines induced by the influenza virus play an important role in the immunological mechanisms underlying influenza virus-GAS superinfection.

In conclusion, any immunological mechanisms induced by influenza virus play an important role in the susceptibility of secondary bacterial infections, such as GAS, in children.

\section{Conflicts of Interest}

The authors declare that there are no conflicts of interest regarding the publication of this article.

\section{Authors' Contributions}

FO, HT, TJ, HM, TM, and $\mathrm{KN}$ managed the patient and prepared the manuscript. EI reviewed the manuscript. All authors have read and approved the final manuscript.

\section{Acknowledgments}

We thank Drs. Hisayuki Shigematsu, Mikio Okazaki, and Yoshifumi Sano, Center of Chest Medicine and Surgery, Ehime University, Ehime, Japan, for surgical treatment including VATS. We also thank Dr. Tadayoshi Ikebe, Department of Bacteriology, National Institute of Infectious Diseases, Tokyo, Japan, for GAS virulence factor gene analysis.

\section{References}

[1] D. L. Stevens, "Invasive group A streptococcus infections," Clinical Infectious Diseases, vol. 14, no. 1, pp. 2-11, 1992.

[2] T. Sakai, D. Taniyama, S. Takahashi, M. Nakamura, and T. Takahashi, "Pleural empyema and streptococcal toxic shock syndrome due to Streptococcus pyogenes in a healthy Spanish traveler in Japan," IDCases, vol. 9, pp. 85-88, 2017.

[3] K. Krenke, E. Urbankowska, T. Urbankowski, J. Lange, and M. Kulus, "Clinical characteristics of 323 children with parapneumonic pleural effusion and pleural empyema due to community acquired pneumonia," Journal of Infection and Chemotherapy, vol. 22, no. 5, pp. 292-297, 2016.
[4] T. Takahashi, K. Sunaoshi, K. Sunakawa et al., "Clinical aspects of invasive infections with Streptococcus dysgalactiae ssp. equisimilis in Japan: differences with respect to Streptococcus pyogenes and Streptococcus agalactiae," Clinical Microbiology and Infection, vol. 16, no. 8, pp. 1097-1103, 2010.

[5] B. K. Eriksson, J. Andersson, S. E. Holm, and M. Norgren, "Invasive group A streptococcal infections: T1M1 isolates expressing pyrogenic exotoxins A and B in combination with selective lack of toxin-neutralizing antibodies are associated with increased risk of streptococcal toxic shock syndrome," Journal of Infectious Diseases, vol. 180, no. 2, pp. 410-418, 1999.

[6] K. Ampofo, A. Herbener, A. J. Blaschke et al., "Association of 2009 pandemic influenza A (H1N1) infection and increased hospitalization with parapneumonic empyema in children in Utah," Pediatric Infectious Disease Journal, vol. 29, no. 10, pp. 905-909, 2010.

[7] K. M. Robinson, J. K. Kolls, and J. F. Alcorn, "The immunology of influenza virus-associated bacterial pneumonia," Current Opinion in Immunology, vol. 34, pp. 59-67, 2015.

[8] K. M. Robinson, S. M. Choi, K. J. McHugh et al., "Influenza A exacerbates Staphylococcus aureus pneumonia by attenuating IL-1 $\beta$ production in mice," Journal of Immunology, vol. 191, no. 10, pp. 5153-5159, 2013.

[9] K. W. Moore, A. O'Garra, R. de Waal Malefyt, P. Vieira, and T. R. Mosmann, "Interleukin-10," Annual Review of Immunology, vol. 11, no. 1, pp. 165-90, 1993.

[10] F. Bedoya, G. S. Cheng, A. Leibow et al., "Viral antigen induces differentiation of Foxp3+ natural regulatory $\mathrm{T}$ cells in influenza virus-infected mice," Journal of Immunology, vol. 190, no. 12, pp. 6115-6125, 2013.

[11] L. A. McNamee and A. G. Harmsen, "Both influenza-induced neutrophil dysfunction and neutrophil-independent mechanisms contribute to increased susceptibility to a secondary Streptococcus pneumoniae infection," Infection and Immunity, vol. 74, no. 12, pp. 6707-6721, 2006.

[12] A. Barthelemy, S. Ivanov, J. Fontaine et al., "Influenza A virusinduced release of interleukin-10 inhibits the anti-microbial activities of invariant natural killer $\mathrm{T}$ cells during invasive pneumococcal superinfection," Mucosal Immunology, vol. 10, no. 2, pp. 460-469, 2017.

[13] K. F. van der Sluijs, L. J. van Elden, M. Nijhuis et al., "IL-10 is an important mediator of the enhanced susceptibility to pneumococcal pneumonia after influenza infection," Journal of Immunology, vol. 172, no. 12, pp. 7603-7609, 2004.

[14] N. Sharma and D. Toor, "Interleukin-10: Role in increasing susceptibility and pathogenesis of rheumatic fever/rheumatic heart disease," Cytokine, vol. 90, pp. 169-176, 2017. 


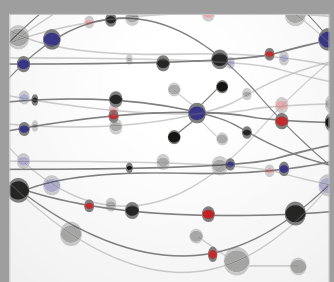

The Scientific World Journal
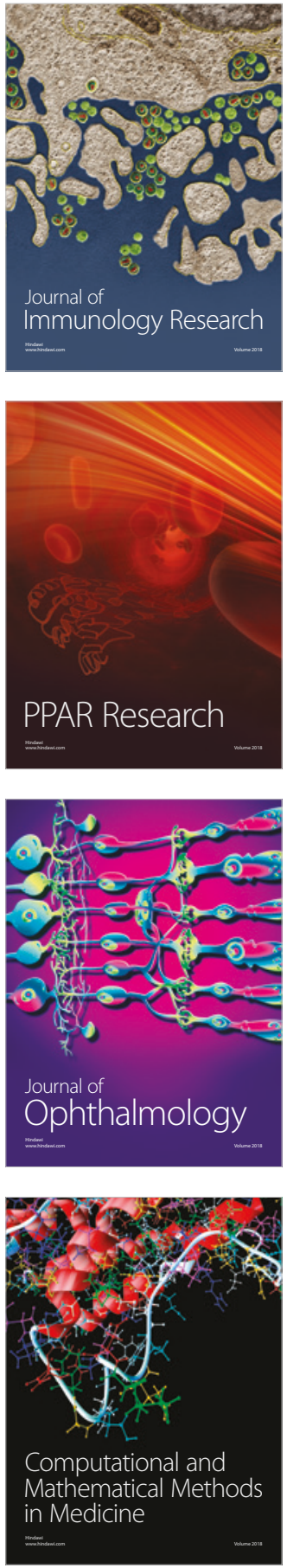

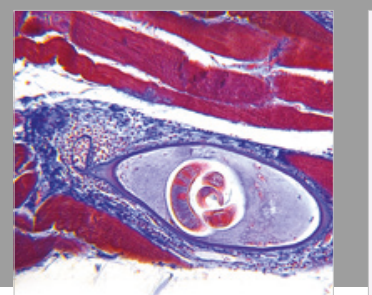

Gastroenterology Research and Practice

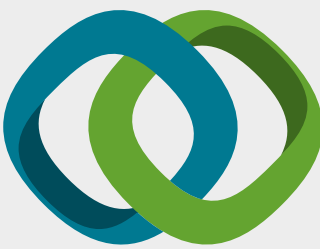

\section{Hindawi}

Submit your manuscripts at

www.hindawi.com
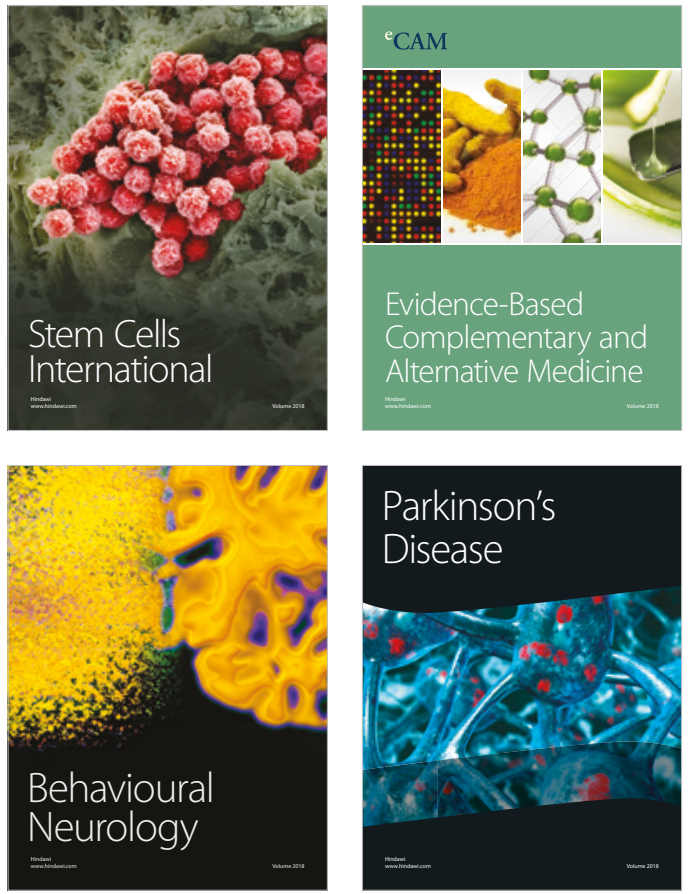

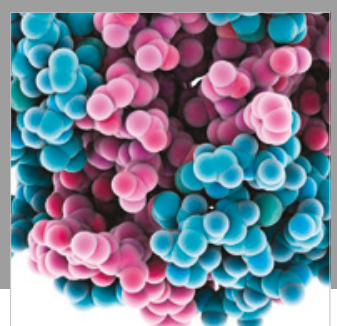

ournal of

Diabetes Research

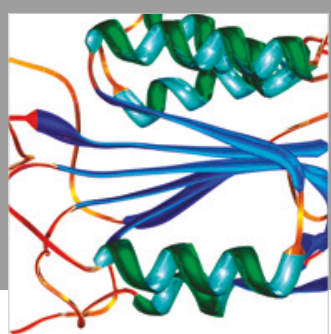

Disease Markers
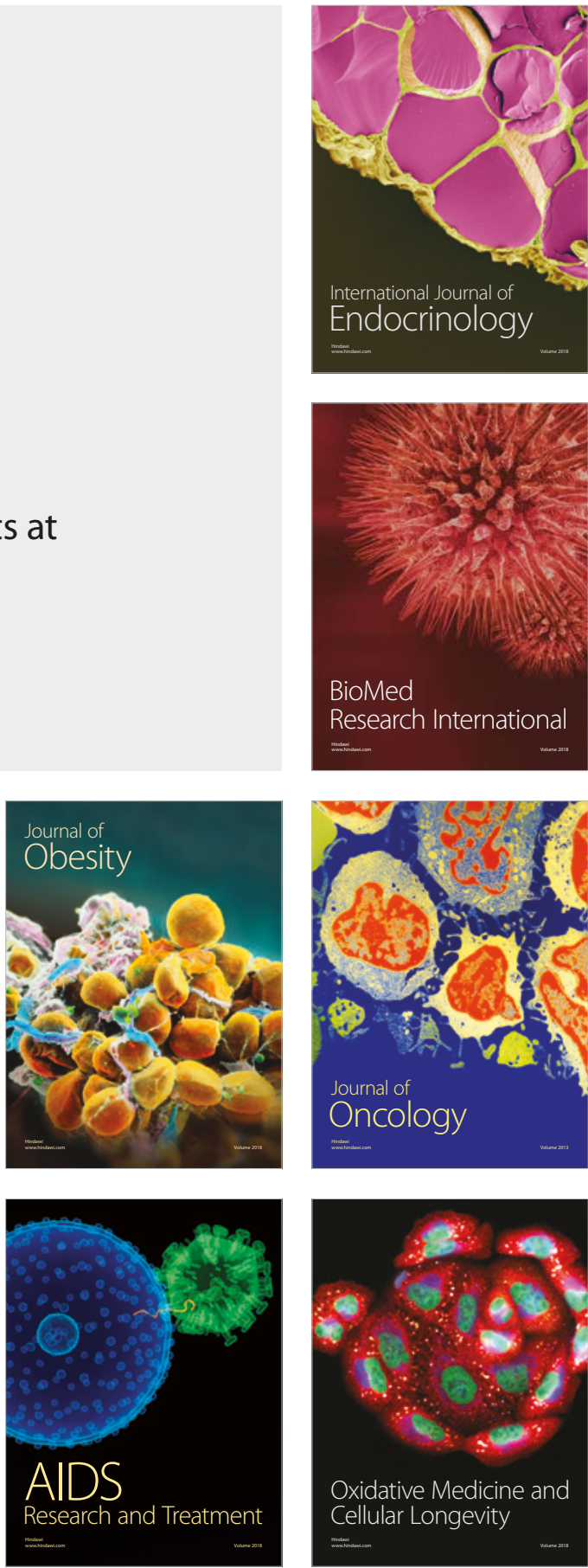